\title{
openheart COVID-19 pandemic is associated with mechanical complications in patients with ST-elevation myocardial infarction
}

\author{
Satoshi Kitahara (D) , , ${ }^{1,2}$ Masashi Fujino, ${ }^{1}$ Satoshi Honda, ${ }^{1}$ Yasuhide Asaumi, ${ }^{1}$ \\ Yu Kataoka, ${ }^{1}$ Fumiyuki Otsuka, ${ }^{1}$ Michio Nakanishi, ${ }^{1}$ Yoshio Tahara, ${ }^{1}$ \\ Soshiro Ogata, ${ }^{3}$ Daisuke Onozuka (D) , ${ }^{3}$ Kunihiro Nishimura, ${ }^{3}$ Tomoyuki Fujita, ${ }^{4}$ \\ Kenichi Tsujita, ${ }^{5}$ Hisao Ogawa, ${ }^{1}$ Teruo Noguchi (iD) 1,2
}

\begin{abstract}
- Additional material is published online only. To view please visit the journal online (http://dx.doi.org/10.1136/ openhrt-2020-001497).

To cite: Kitahara S, Fujino M, Honda S, et al. COVID-19 pandemic is associated with mechanical complications in patients with ST-elevation myocardial infarction. Open Heart 2021;8:e001497. doi:10.1136/ openhrt-2020-001497
\end{abstract}

Received 28 0ctober 2020 Revised 31 December 2020 Accepted 18 January 2021

Check for updates

(c) Author(s) (or their employer(s)) 2021. Re-use permitted under CC BY-NC. No commercial re-use. See rights and permissions. Published by BMJ.

For numbered affiliations see end of article.

Correspondence to Dr Masashi Fujino; fujinom@ ncvc.go.jp

\section{ABSTRACT}

Objective Although there are regional reports that the COVID-19 pandemic is associated with a reduction in acute myocardial infarction presentations and primary percutaneous coronary intervention (PCI) procedures, little is known about the impact of the COVID-19 pandemic on mechanical complications resulting from ST-segment elevation myocardial infarction (STEMI) and mortality. Methods This single-centre retrospective cohort study analysed presentations, incidence of mechanical complications, and mortality in patients with STEMI before and after a state of emergency was declared due to the COVID-19 pandemic by the Japanese government on 7 April 2020.

Results We analysed 359 patients with STEMI hospitalised before the declaration and 63 patients hospitalised after the declaration. The proportion of patients with late presentation was significantly higher after the declaration than before $(25.4 \%$ vs $14.2 \%$, $\mathrm{p}=0.03)$. The incidence of late presentation was significantly higher during the COVID-19 pandemic than before (incidence rate ratio (IRR), 2.41; $95 \% \mathrm{Cl}, 1.37$ to $4.05 ; p=0.001$, even after adjusting for month (IRR, $2.61 ; 95 \% \mathrm{Cl}, 1.33$ to $5.13 ; p<0.01)$. Primary $\mathrm{PCl}$ was performed significantly less often after the declaration than before $(68.3 \%$ vs $82.5 \%, p=0.009)$. The mechanical complication resulting from STEMI occurred in 13 of 359 (3.6\%) patients before the declaration and 9 of $63(14.3 \%)$ patients after the declaration $(p<0.001)$. However, the incidence of in-hospital death (before, $6.2 \%$ vs after, $6.4 \%$, $\mathrm{p}=0.95$ ) was comparable.

Conclusions Following the COVID-19 pandemic, an increased incidence of mechanical complications resulting from STEMI was observed. Instructing people to stay at home, without effectively educating them to immediately seek medical attention when suffering symptoms of a heart attack, may worsen outcomes in patients with STEMI.

\section{INTRODUCTION}

Osaka prefecture is the second epicentre of the COVID-19 pandemic in Japan. The WHO declared a COVID-19 pandemic on 11 March 2020. In response to this statement, Japan

\section{Key questions}

What is already known about this subject?

- Little is known about the impact of the COVID-19 pandemic on mechanical complications resulting from ST-segment elevation myocardial infarction (STEMI) and mortality.

What does this study add?

- Our analysis of 422 consecutive patients with STEM showed that the incidence of mechanical complications increased fourfold after a state of emergency was declared for the COVID-19 pandemic when compared with historical controls.

- However, in-hospital mortality did not increase (before, $6.2 \%$ vs after, $6.4 \%, p=0.95)$.

How might this impact on clinical practice?

- In the case of diseases such as STEMI, where the time course affects prognosis, emergency medical services (EMS) activation at the right time is necessary and individuals need to be educated to call EMS appropriately.

declared a state of emergency on 7 April 2020 and instructed people to stay at home.

Although there are regional reports that the COVID-19 pandemic is associated with a reduction in both acute myocardial infarction (AMI) presentations and primary percutaneous coronary intervention (PCI) procedures ${ }^{1-7}$ little is known about the impact of the COVID-19 pandemic on mechanical complications resulting from ST-segment elevation myocardial infarction (STEMI) and mortality. If patients with STEMI stay home, there may be a delay in presentation, leading to worsening symptoms or a higher incidence of mechanical complications.

Therefore, we hypothesised that patients with STEMI during the COVID-19 pandemic have been delayed hospital arrival and subsequently poorer prognosis than a historical cohort of patients with STEMI. To address this 
question, we compared mortality, prevalence of delayed hospital arrival and incidence of mechanical complications resulting from STEMI before versus after a state of emergency was declared for the COVID-19 pandemic in Japan.

\section{METHODS}

\section{Study design, population and outcomes}

The study population was extracted from an observational single-centre registry of patients with AMI admitted to the National Cerebral and Cardiovascular Center of Japan. This registry has enrolled consecutive patients with AMI since 2001 and its findings have been previously published. $^{8-10}$

We conducted a retrospective cohort study of patients with STEMI between 7 April 2020, the day that a state of emergency was declared for the COVID-19 pandemic, and 14 August 2020. Patients with STEMI between 1 January 2018 and 6 April 2020 were included in the historical cohort. AMI was defined according to the fourth universal definition of myocardial infarction. ${ }^{11}$ Briefly, patients with AMI should have ischaemic changes based on cardiac troponin values with at least 1 value above the 99th percentile upper reference limit and present with ischaemic symptoms such as chest pain lasting longer than 30 min or new ischaemic electrocardiographic signs. ST elevation should be a new finding at the J-point in two contiguous leads with a cut-point of $\geq 1 \mathrm{~mm}$ in all leads other than leads V2-V3, where the following cut-points apply: $\geq 2 \mathrm{~mm}$ in men aged $\geq 40$ years, $\geq 2.5 \mathrm{~mm}$ in men aged $<40$ years or $\geq 1.5 \mathrm{~mm}$ in women regardless of age. This study included patients who were admitted within 2 weeks after the onset of AMI and type 1 or type 2 myocardial infarction. Late presentation was defined as onset-todoor time longer than 24 hours because the indication for primary PCI was limited to onset-to-door time longer than 24 hours. ${ }^{12-14}$ The allocation of emergency coronary angiography, coronary intervention and surgical treatment was determined by the attending physician or heart team according to guidelines. ${ }^{12-14}$ The definition of primary PCI was urgent balloon angioplasty (with or without stenting) without the use of fibrinolytic therapy to open the infarct-related artery during acute STEMI. ${ }^{15}$

The primary outcome was the incidence of mechanical complications during hospitalisation in patients with STEMI before and after the declaration in Japan. Secondary outcomes were onset-to-door time, treatment management (revascularisation and circulatory assist device use) and in-hospital outcomes (death and length of hospitalisation). Mechanical complications consisted of acute free wall rupture, contained rupture, ventricular septal rupture and papillary muscle rupture. Definitions of mechanical complications were previously reported. ${ }^{16}$ In brief, acute free wall rupture was defined as an abrupt transmural tear of the infarcted area causing hemopericardium, cardiac tamponade and death in $<30 \mathrm{~min}$ without emergent surgical treatment. Contained rupture was defined as a gradual or incomplete tear or erosion of the infarcted area with slow bleeding into the pericardial sac causing progressive or recurrent cardiac tamponade. Ventricular septal rupture was diagnosed with colour Doppler echocardiography showing abnormal shunting via the interventricular septum or a significant increase in oxygen saturation in the right ventricle. Papillary muscle rupture was diagnosed based on echocardiographic findings of tears in the papillary muscle or chordae tendineae causing acute mitral regurgitation.

Data were abstracted from medical records. Age; sex; comorbidities such as hypertension, diabetes and dyslipidaemia; smoking status; history of myocardial infarction; prior revascularisation; onset-to-door time and Killip classification were recorded on admission. Chronic kidney disease was defined as an estimated glomerular filtration rate $\leq 60 \mathrm{~mL} / \mathrm{min} / 1.73 \mathrm{~m}^{2}$ in this study.

\section{Statistical analysis}

Non-normally distributed continuous data were summarised as medians (IQR) and compared using the Wilcoxon rank sum test. Categorical variables were compared using the $\chi^{2}$ test or Fisher's exact test as appropriate. To investigate the association between the declaration and late presentation, we used Poisson regression with the number of late presentations per 2 weeks as a dependent variable, timing relative to the declaration (before or after) as an independent variable of interest, month as an independent variable (covariate) and logarithm of the population size of Osaka prefecture in August 2019 as an offset term. We exponentiated regression coefficients obtained from the Poisson regression analysis to show incidence rate ratios (IRRs) for late presentation by timing relative to the declaration. Logistic regression analysis was used to obtain ORs and 95\% CIs for primary and secondary outcomes. We performed multivariate analysis to adjust for baseline variables, including established risk factors for mechanical complications (age, female sex, anterior myocardial infarction, de novo myocardial infarction and single-vessel disease $)^{16-19}$ and timing relative to the declaration (model 1 ). Model 2 included factors that were significant in the univariate analysis and established risk factors for mechanical complications. For sensitivity analysis, any variable with $\mathrm{p}<0.05$ during univariate analysis was included in a multivariate model to identify independent predictors of the primary outcome. Late presentation was not included in the multivariate analysis of the primary outcome to avoid overfitting. Late presentation was considered an intermediate variable in the relationship between the declaration and mechanical complications. Intermediate variables should not be adjusted because it will lead to overadjustment. ${ }^{20} \mathrm{P}$ values of $<0.05$ were considered statistically significant. Statistical analysis was performed using JMP (V.11.0, SAS Institute) except for the analysis of IRR, which was performed using R statistical software (V.4.0.2, The R Foundation). 


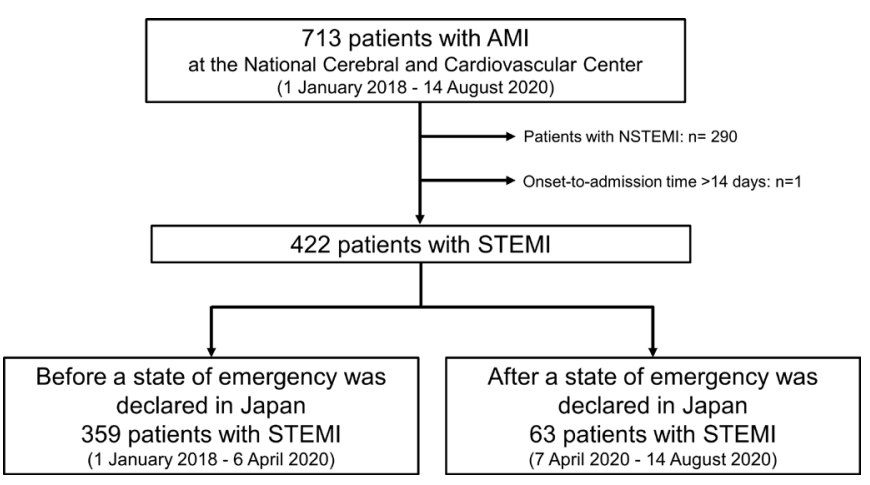

Figure 1 Study flow chart. AMI, acute myocardial infarction; NSTEMI, non-ST-segment elevation myocardial infarction; STEMI, ST-segment elevation myocardial infarction.

\section{RESULTS}

This study included 713 patients with AMI. We excluded patients with non-STEMI $(n=290)$ and patients with STEMI who presented more than 2 weeks $(n=1)$ after onset. Ultimately, we analysed 422 patients with STEMI (figure 1). After a state of emergency was declared for Osaka, 63 patients with STEMI were admitted to our hospital. In this cohort, COVID-19 PCR testing was performed in 56 patients; all PCR tests were negative. Table 1 shows the baseline characteristics of patients before and after the declaration. Compared with before the declaration, a significantly lower proportion of patients after the declaration had hypertension $(\mathrm{p}=0.04)$, but there were no significant differences in age, sex, smoking status, chronic kidney disease or previous coronary revascularisation between the groups.

Clinical outcomes are shown in table 2. Onset-todoor time was significantly longer during COVID-19 pandemic than before the declaration (2.4 (1.0-8.1) vs 4.1 (1.3-24.5) hours, $\mathrm{p}=0.02)$; furthermore, $16(25.4 \%)$ patients after the declaration had a late presentation; this proportion was significantly higher than the proportion observed before the declaration $(n=51,14.2 \% ; \mathrm{p}=0.03)$. Primary PCI was performed significantly less often in patients after the declaration compared with before $(\mathrm{n}=43,68.3 \%$ vs $\mathrm{n}=296,82.5 \%, \mathrm{p}=0.009)$. There were twelve and four patients not treated with primary PCI before and after the declaration, respectively. Before the declaration, the reasons for not undergoing primary PCI were vasospastic angina $(n=3)$, coronary artery bypass grafting $(n=2)$ surgery for the mechanical complications $(n=2)$, patient condition $(n=2)$, distal culprit lesion $(n=1)$, operator's decision $(n=1)$ and not obtained consent for PCI $(n=1)$. After the declaration, the reasons were vasospastic angina $(n=1)$, spontaneous coronary artery dissection $(n=1)$, distal culprit lesion $(n=1)$ and coronary artery bypass grafting $(n=1)$. There were no patients treated with fibrinolysis in all study patients. The primary outcome of mechanical complications occurred in 22 of 422 patients $(5.2 \%)$. It occurred in 13 of 359 patients before the declaration $(3.6 \%)$ and 9 of 63 patients after the declaration (14.3\%; $<<0.001)$. Acute free wall rupture, contained rupture, ventricular septal rupture and papillary muscle rupture occurred in one $(0.3 \%)$, six $(1.7 \%)$, four $(1.1 \%)$ and two $(0.6 \%)$ patients before the declaration, and three $(4.8 \%)$, three $(4.8 \%)$, three $(4.8 \%)$ and zero patients after the declaration, respectively. In-hospital mortality (before, 6.2\% vs after, 6.4\%; p=0.95) and cause of death were comparable among patients before and after the declaration.

Among 22 patients who reached the primary outcome (online supplemental table 1), 3 of 13 patients (patients 4, 7 and 12) before the declaration and 1 of 9 patients (patient 19) after the declaration did not receive surgical treatment due to his or her medical condition or the heart

Table 1 Baseline characteristics and clinical presentation

\begin{tabular}{|c|c|c|c|c|c|}
\hline \multirow[b]{2}{*}{ Age, median (IQR), years } & \multicolumn{2}{|c|}{$\begin{array}{l}\text { Before a state of emergency } \\
\text { declaration }(n=359)\end{array}$} & \multicolumn{2}{|c|}{$\begin{array}{l}\text { After a state of emergency } \\
\text { declaration }(n=63)\end{array}$} & \multirow{2}{*}{$\begin{array}{l}\text { P value } \\
0.19\end{array}$} \\
\hline & 72 & $(61-80)$ & 70 & $(59-79)$ & \\
\hline Body mass index, median (IQR), $\mathrm{kg} / \mathrm{m}^{2}$ & 23.2 & $(21.0-25.8)$ & 23.2 & $(21.4-25.2)$ & 0.85 \\
\hline Current smoker, n (\%) & 122 & $(34.0)$ & 23 & $(36.5)$ & 0.69 \\
\hline Diabetes mellitus, $\mathrm{n}(\%)$ & 136 & $(37.9)$ & 16 & $(25.4)$ & 0.06 \\
\hline Chronic kidney disease, n (\%) & 171 & $(47.6)$ & 31 & $(49.2)$ & 0.82 \\
\hline De novo myocardial infarction, $\mathrm{n}(\%)$ & 330 & $(91.9)$ & 55 & $(87.3)$ & 0.23 \\
\hline Prior PCl, n (\%) & 33 & $(9.2)$ & 6 & $(9.5)$ & 0.93 \\
\hline
\end{tabular}

$P$ values refer to the comparisons between the two groups.

$\mathrm{CABG}$, coronary artery bypass grafting; $\mathrm{PCl}$, percutaneous coronary intervention. 
Table 2 Procedural characteristics, clinical presentations and outcomes

\begin{tabular}{|c|c|c|c|c|c|}
\hline \multirow[b]{2}{*}{ Onset-to-door time, median (IQR), hours } & \multicolumn{2}{|c|}{$\begin{array}{l}\text { Before a state of } \\
\text { emergency declaration } \\
(n=359)\end{array}$} & \multicolumn{2}{|c|}{$\begin{array}{l}\text { After a state of emergency } \\
\text { declaration }(n=63)\end{array}$} & \multirow{2}{*}{$\frac{\text { P value }}{0.02}$} \\
\hline & 2.4 & $(1.0-8.1)$ & 4.1 & $(1.3-24.5)$ & \\
\hline Late presentation, n (\%) & 51 & $(14.2)$ & 16 & $(25.4)$ & 0.03 \\
\hline Killip classification at admission & & & & & 0.04 \\
\hline $\mathrm{I}, \mathrm{n}(\%)$ & 290 & $(80.8)$ & 43 & $(68.3)$ & \\
\hline II, n (\%) & 8 & $(2.2)$ & 4 & $(6.3)$ & \\
\hline III, n (\%) & 11 & $(3.1)$ & 1 & $(1.6)$ & \\
\hline IV, n (\%) & 50 & $(13.9)$ & 15 & $(23.8)$ & \\
\hline Primary PCl, n (\%) & 296 & $(82.5)$ & 43 & $(68.3)$ & 0.009 \\
\hline Emergent CABG, $\mathrm{n}(\%)$ & 6 & $(1.7)$ & 2 & $(3.2)$ & 0.42 \\
\hline Mechanical complications, n (\%) & 13 & $(3.6)$ & 9 & $(14.3)$ & $<0.001$ \\
\hline Free wall rupture, n (\%) & 1 & $(0.3)$ & 3 & $(4.8)$ & \\
\hline Contained rupture, $\mathrm{n}(\%)$ & 6 & $(1.7)$ & 3 & $(4.8)$ & \\
\hline Ventricular septal rupture, $\mathrm{n}(\%)$ & 4 & $(1.1)$ & 3 & $(4.8)$ & \\
\hline Papillary muscle rupture, $\mathrm{n}(\%)$ & 2 & $(0.6)$ & 0 & $(0)$ & \\
\hline Use of circulatory assist devices, $n(\%)$ & 62 & $(17.3)$ & 15 & $(23.8)$ & 0.22 \\
\hline Surgical treatment for mechanical complications, $\mathrm{n}(\%)$ & $10 / 13$ & $(76.9)$ & $8 / 9$ & $(88.9)$ & 0.47 \\
\hline Cardiogenic embolism, n (\%) & 11 & $(3.1)$ & 1 & $(1.6)$ & 0.51 \\
\hline Left ventricular thrombus, $\mathrm{n}(\%)$ & 8 & $(2.2)$ & 1 & $(1.6)$ & 0.74 \\
\hline In-hospital death & 22 & $(6.2)$ & 4 & $(6.4)$ & 0.95 \\
\hline Cause of death & & & & & 0.74 \\
\hline Cardiac death & 13 & $(59.1)$ & 2 & $(50.0)$ & \\
\hline Non-cardiac death & 9 & $(40.9)$ & 2 & $(50.0)$ & \\
\hline Hospital stay, median (IQR), days & 14 & $(11-20)$ & 18 & $(14-33)$ & 0.001 \\
\hline
\end{tabular}

$P$ values refer to the comparisons between the two groups.

CABG, coronary artery bypass grafting; $\mathrm{PCI}$, percutaneous coronary intervention.

team's decision. All of these four patients died during hospitalisation. Among the 18 patients who received surgical treatment, 4 of 10 patients before the declaration and 1 of 8 patients after the declaration died. Hospital stay was significantly longer in patients after the declaration compared with before the declaration (14 (11-20) vs 18 (14-33) days; $\mathrm{p}=0.001)$. In Poisson regression analyses, the incidence of late STEMI presentation was higher during the COVID-19 pandemic period compared with the incidence before the declaration (IRR, 2.41; 95\% CI, 1.37 to $4.05 ; \mathrm{p}=0.001$ ) and also higher than during the same time period in 2018-2019 for both periods (IRR, $3.20 ; 95 \% \mathrm{CI}, 1.61$ to $6.44 ; \mathrm{p}=0.001)$. IRRs remained significant after adjusting for month (IRR, 2.61; 95\% CI, 1.33 to $5.13 ; \mathrm{p}<0.001$ and IRR, 3.00 ; $95 \%$ CI, 1.48 to 6.26 ; $\mathrm{p}=0.003$, respectively).

Compared with before the declaration, the pandemic period was associated with a twofold increase in the risk of late presentation (OR, 2.06; 95\% CI, 1.08 to 3.90; $\mathrm{p}=0.03$ ) and a fourfold increase in the risk of mechanical complications (OR, 4.44; 95\% CI, 1.80 to $10.88 ; \mathrm{p}=0.002$ ). Table 3 shows univariate and multivariate results for the primary outcome. In the multivariate analysis, the pandemic period was independently associated with the primary outcome (OR, 5.32; 95\% CI, 2.01 to 14.03; $\mathrm{p}=0.001$ in model 1 and OR, 5.78; $95 \%$ CI, 2.08 to 16.05 ; $\mathrm{p}=0.001$ in model 2 ). In sensitivity analysis, when any variable with $\mathrm{p}<0.05$ in the univariate analysis was included in a multivariate model, pandemic period was an independent predictor for the primary outcome (OR, 4.90; $95 \%$ CI, 1.84 to $13.05 ; \mathrm{p}=0.001$ ).

\section{DISCUSSION}

Our analysis of the impact of the COVID-19 pandemic on outcomes in patients with STEMI has several key findings. First, fewer primary PCI procedures, longer onset-to-door time and a larger proportion of late presentations among patients with STEMI were observed after the declaration of a state of emergency in Japan on 7 April 2020. Second, after adjusting for differences in baseline characteristics and established risk factors for mechanical complications due to STEMI, the incidence of mechanical complications of STEMI increased fivefold after the declaration, even though there were no significant differences with respect to in-hospital mortality. Our study is the first to 
Table 3 Univariate and multivariate logistic analysis of risk factors for mechanical complications

\begin{tabular}{|c|c|c|c|c|c|c|c|c|c|}
\hline & \multicolumn{3}{|c|}{ Univariate analysis } & \multicolumn{3}{|c|}{$\begin{array}{l}\text { Multivariate analysis model } \\
1^{*}\end{array}$} & \multicolumn{3}{|c|}{$\begin{array}{l}\text { Multivariate analysis model } \\
2 \dagger\end{array}$} \\
\hline & OR & $95 \% \mathrm{Cl}$ & $P$ value & OR & $95 \% \mathrm{Cl}$ & $P$ value & OR & $95 \% \mathrm{Cl}$ & $P$ value \\
\hline Female sex & 3.90 & 1.62 to 9.40 & 0.002 & 3.41 & 1.29 to 9.04 & 0.01 & 3.54 & 1.29 to 9.73 & 0.01 \\
\hline Body mass index & 0.97 & 0.87 to 1.09 & 0.65 & & & & & & \\
\hline Diabetes mellitus & 1.24 & 0.52 to 2.98 & 0.62 & & & & & & \\
\hline Dyslipidaemia & 0.58 & 0.24 to 1.38 & 0.22 & & & & & & \\
\hline Chronic kidney disease & 7.51 & 2.19 to 25.78 & 0.001 & & & & 7.27 & 1.94 to 27.30 & 0.003 \\
\hline De novo myocardial infarction & 2.08 & 0.27 to 15.89 & 0.48 & 1.90 & 0.22 to 15.88 & 0.55 & 2.49 & 0.28 to 22.26 & 0.41 \\
\hline
\end{tabular}

*Multivariate logistic regression analysis with established risk factors for mechanical complications (age, female, anterior myocardial infarction, de novo myocardial infarction, single-vessel disease and after a state of declaration (vs before)). †Multivariate logistic regression analysis with factors that were significant in the univariate analysis and established risk factors for mechanical complications.

show an increased incidence of mechanical complications in patients with STEMI due to late presentation during the COVID-19 pandemic. These findings suggest that behavioural changes in response to the crisis may lead to less healthcare utilisation, which may adversely influence STEMI outcomes.

The COVID-19 pandemic has led to radical transformation of social, economic and healthcare networks, which may have profound indirect consequences on clinical presentation and management of patients with STEMI. According to a report from Milan, Italy, the COVID-19 pandemic has significantly increased the proportion of patients with late presentation $(50.0 \%$ vs $4.8 \%$; $\mathrm{p}<0.01)$ and decreased the rate of primary PCI $(80.8 \%$ vs $100 \%$, $\mathrm{p}=0.06) .{ }^{7}$ In another survey of 73 centres in Spain, ${ }^{5}$ there was an estimated $40 \%$ reduction in procedures performed in the STEMI setting. There was an estimated 38\% reduction in cardiac catheterisation laboratory STEMI activations in the USA. ${ }^{2}$ Our study shows a $17 \%$ reduction in primary PCI procedures for STEMI after the declaration of the COVID-19 pandemic. Although a higher incidence of late presentation and a lower rate of primary PCI are associated with established risk factors for mechanical complications such as cardiac rupture and ventricular septum rupture, ${ }^{1516}$ there have been no previous reports of an increased rate of mechanical complications during the COVID-19 pandemic.

Our study focused on the incidence of mechanical complications in patients with STEMI after the declaration. Therefore, we adjusted for prognostic factors potentially associated with mechanical complications in patients with STEMI, including high age, female sex, single-vessel disease, de novo myocardial infarction and presence of hypertension. In the analysis, we did not include late presentation, which is an established risk factor for mechanical complications, to avoid overfitting. We considered late presentation to be an intermediate variable in the relationship between the declaration and mechanical complications. As shown in table 2, late presentation was significantly more common in patients after the declaration than in the 2 years prior. In addition, when we included the declaration as a variable in multivariate logistic regression models with mechanical complications as an outcome, the declaration was significantly associated with mechanical complications. These findings suggest that due to the stay-at-home request by the government in response to the COVID-19 pandemic, individuals may not be requesting emergency medical services (EMS) properly based on the fear of COVID-19. It has also been reported that stay-at-home orders influence mental health. ${ }^{21}$ For diseases such as STEMI and stroke, in which the time course affects prognosis, EMS activation at the right time is necessary. Individuals need to be educated to call EMS appropriately to prevent delayed hospital presentation. Therefore, the global medical community needs to address public concerns and stress the importance of seeking prompt medical attention for symptoms of heart attack and stroke.

Our study has several limitations. First, this is an observational study in a single centre with a small number of patients examined. Therefore, there may be inherent flaws related to selection bias, spurious observations, unmeasured covariates and non-random allocation to treatment. Second, our institution is the only 
government-designated advanced cardiovascular centre in Japan and one of the major hospitals able to perform PCI in the northern part of Osaka prefecture. Therefore, the population of this study did not reflect all patients residing in this area. Third, post-discharge follow-up data were not available. Finally, despite a significant increase in the number of mechanical complications, there were no significant differences observed in in-hospital mortality. These conflicting results might be explained by the low number of in-hospital mortality events and the small sample size of this study. A report from New York City showed a decline in the number of patients with myocardial infarction arriving at the hospital. Patients with cardiac rupture due to myocardial infarction who survived presented to the hospital, whereas patients with rupture who did not survive may have not reached the hospital and died at home. Further research is needed to evaluate mortality in patients with STEMI during the COVID-19 pandemic.

In conclusion, our analysis demonstrates that the incidence of mechanical complications was fourfold higher due to late presentation after a state of emergency was declared because of the COVID-19 pandemic in Japan. Although the rates of late presentation and mechanical complications due to STEMI increased after the declaration, we did not demonstrate any in-hospital mortality differences during the COVID-19 pandemic.

\section{Author affiliations \\ ${ }^{1}$ Department of Cardiovascular Medicine, National Cerebral and Cardiovascular Center, Suita, Osaka, Japan \\ 2Department of Advanced Cardiovascular Medicine, Graduate School of Medical Sciences, Kumamoto University, Kumamoto, Japan \\ ${ }^{3}$ Department of Preventive Medicine and Epidemiology, National Cerebral and Cardiovascular Center, Suita, Osaka, Japan \\ ${ }^{4}$ Department of Cardiovascular Surgery, National Cerebral and Cardiovascular Center, Suita, Osaka, Japan \\ ${ }^{5}$ Department of Cardiovascular Medicine, Graduate School of Medical Sciences, Kumamoto University, Kumamoto, Japan}

Contributors SK and MF were responsible for the study design and concept. SK, TF, YT and YA collected the patient data. SH, YA, YK and MN performed the data cleaning. SK, SO, DO and KN performed the data analysis. SK and MF wrote the first draft of the manuscript with support from KT and HO. TN supervised the project.

Funding This study is supported by the grant of the Brisrol Myers Squibb K.K. Competing interests None declared.

Patient consent for publication Not required.

Ethics approval The study protocol was approved by the institutional review board of the National Cerebral and Cardiovascular Center (M-24-055). The study was conducted in accordance with regulations governing epidemiological studies issued by the Ministry of Health, Labour and Welfare of Japan.

Provenance and peer review Not commissioned; externally peer reviewed.

Data availability statement Data may be obtained from a third party and are not publicly available.

Open access This is an open access article distributed in accordance with the Creative Commons Attribution Non Commercial (CC BY-NC 4.0) license, which permits others to distribute, remix, adapt, build upon this work non-commercially, and license their derivative works on different terms, provided the original work is properly cited, appropriate credit is given, any changes made indicated, and the use is non-commercial. See: http://creativecommons.org/licenses/by-nc/4.0/.
ORCID iDs

Satoshi Kitahara http://orcid.org/0000-0002-6073-1302

Daisuke Onozuka http://orcid.org/0000-0001-9596-9188

Teruo Noguchi http://orcid.org/0000-0001-5372-4932

\section{REFERENCES}

1 De Rosa S, Spaccarotella C, Basso C, et al. Reduction of hospitalizations for myocardial infarction in Italy in the COVID-19 era. Eur Heart J 2020;41:2083-8.

2 Garcia S, Albaghdadi MS, Meraj PM, et al. Reduction in STsegment elevation cardiac catheterization laboratory activations in the United States during COVID-19 pandemic. J Am Coll Cardiol 2020;75:2871-2.

3 Kwok CS, Gale CP, Kinnaird T, et al. Impact of COVID-19 on percutaneous coronary intervention for ST-elevation myocardial infarction. Heart 2020;106:1805-11.

4 Metzler B, Siostrzonek P, Binder RK, et al. Decline of acute coronary syndrome admissions in Austria since the outbreak of COVID-19: the pandemic response causes cardiac collateral damage. Eur Heart $J$ 2020;41:1852-3.

5 Rodríguez-Leor O, Alvarez-Álvarez B, Ojeda S. Impact of the COVID-19 pandemic on interventional cardiology activity in Spain. REC: interventional cardiology (English edition, 2020.

6 Solomon MD, McNulty EJ, Rana JS, et al. The Covid-19 pandemic and the incidence of acute myocardial infarction. $N$ Engl $\mathrm{J}$ Med 2020;383:691-3.

7 Gramegna M, Baldetti L, Beneduce A, et al. St-Segment-Elevation myocardial infarction during COVID-19 pandemic: insights from a regional public service healthcare hub. Circ Cardiovasc Interv 2020;13:e009413.

8 Fujino M, Ishihara M, Honda S, et al. Impact of acute and chronic hyperglycemia on in-hospital outcomes of patients with acute myocardial infarction. Am J Cardiol 2014;114:1789-93.

9 Doi T, Kataoka Y, Noguchi T, et al. Coronary artery ectasia predicts future cardiac events in patients with acute myocardial infarction. Arterioscler Thromb Vasc Biol 2017;37:2350-5.

10 Maniwa N, Fujino M, Nakai M, et al. Anticoagulation combined with antiplatelet therapy in patients with left ventricular thrombus after first acute myocardial infarction. Eur Heart J 2018;39:201-8.

11 Thygesen K, Alpert JS, Jaffe AS, et al. Fourth universal definition of myocardial infarction (2018). J Am Coll Cardiol 2018;72:2231-64.

12 Ibanez B, James S, Agewall S, et al. 2017 ESC guidelines for the management of acute myocardial infarction in patients presenting with ST-segment elevation: the task force for the management of acute myocardial infarction in patients presenting with ST-segment elevation of the European Society of cardiology (ESC). Eur Heart $J$ 2018;39:119-77.

13 O'Gara PT, Kushner FG, Ascheim DD, et al. 2013 ACCF/AHA guideline for the management of ST-elevation myocardial infarction: a report of the American College of cardiology Foundation/American heart association Task force on practice guidelines. Circulation 2013;127:e362-425.

14 Kimura K, Kimura T, Ishihara M, et al. JCS 2018 guideline on diagnosis and treatment of acute coronary syndrome. Circ $J$ 2019;83:1085-196.

15 Keeley EC, Hillis LD. Primary PCI for myocardial infarction with STsegment elevation. N Engl J Med 2007;356:47-54.

16 Honda S, Asaumi Y, Yamane T, et al. Trends in the clinical and pathological characteristics of cardiac rupture in patients with acute myocardial infarction over 35 years. J Am Heart Assoc 2014;3:e000984.

17 Rasmussen S, Leth A, Kjøller E, et al. Cardiac rupture in acute myocardial infarction. A review of 72 consecutive cases. Acta Med Scand 1979;205:11-16.

18 Figueras J, Curos A, Cortadellas J, et al. Relevance of electrocardiographic findings, heart failure, and infarct site in assessing risk and timing of left ventricular free wall rupture during acute myocardial infarction. Am J Cardiol 1995;76:543-7.

19 Figueras J, Alcalde O, Barrabés JA, et al. Changes in hospital mortality rates in 425 patients with acute ST-elevation myocardial infarction and cardiac rupture over a 30 -year period. Circulation 2008;118:2783-9.

20 Schisterman EF, Cole SR, Platt RW. Overadjustment bias and unnecessary adjustment in epidemiologic studies. Epidemiology 2009;20:488-95.

21 Jacobson NC, Lekkas D, Price G, et al. Flattening the mental health curve: COVID-19 Stay-at-Home orders are associated with alterations in mental health search behavior in the United States. JMIR Ment Health 2020;7:e19347. 